\title{
Using Activity Analysis to Identify Individual and Group Behavioral Constraints to Organizational Change Management
}

\author{
Mohammed-Aminu Sanda \\ Department of Business Administration, Technology and Social Sciences \\ Luleå University of Technology, SE - 97187, Luleå, Sweden \\ Tel: 46-920-493-025 E-mail:mohami@1tu.se
}

Received: April 24, $2011 \quad$ Accepted: June 7, $2011 \quad$ doi:10.5539/jms.v1n1p111

\begin{abstract}
This article looks at the constraining influence of internal organizational factors on the management of organizational change. The purpose of the study was to determine the individual and group behavioral-induced situational problems, conflicts and tensions that change managers can identify and also use as innovative tools to enhance their capacity to manage organizational change. Individual and group behavioral factors that constrained the implementation and internalization of a best management practice model in an organization were examined. It is argued that in the organizational change process, the inability of change managers to simultaneously identify the development of situational problems, such as conflicts and tensions induced by individual and group based behaviours, and exploiting them as tools to enhance management innovation, is a significant constraint. It is concluded that; by continuously examining individual and group based mediated actions, managers can understand, identify, isolate and manage situational problems in future implementation and internalization of new practices models in their organizations.
\end{abstract}

Keywords: Organizational change, Change management, Organizational activity system, Activity contradiction, Individual and group behaviours.

\section{Introduction}

Research and Technology Organizations (RTO) in many developing countries are state-owned institutions that provide research and development $(\mathrm{R} \& \mathrm{D})$ assistance to small and medium scale enterprises (SME). The ability of RTOs to serve SMEs effectively is an important determinant to the SMEs' capacities to overcome the competitive challenge of the marketplace. The RTOs are expected to provide efficient and effective services to the SMEs that can enhance their (i.e. SMEs) capacities towards competitiveness and sustainability (Mengu \& Grier, 1999). But over the years, most RTOs in developing countries operated inefficiently and provided ineffective service to the SMEs. The key impediment to the RTOs' performances being efficient and their service delivery to the SMEs being effective was not technology oriented, but rather management oriented (Mengu \& Grier, 1999).

A study by Mengu and Grier (1999) on the operations of Europe-based RTOs revealed a great deal of business and management practices they used to enhance service delivery to their clients, SMEs included. Mengu and Grier (1999) categorized the practices into the following ten management process areas; - (i) governance, (ii) RTO services, (iii) business development, (iv) organization management, (v) project management, (vi) policy and programming, (vii) capacity building, (viii) financial management, (ix) personnel management, and (x) networking. Mengu and Grier (1989) reported that practices in these ten management areas were benchmarked and used by most RTOs in developing countries as organizational change tool to enhance their efficiency and effectiveness towards service delivery. But according to Mengu and Grier (1989), their studies on the attempted internalization of the ten management practices by these RTOs showed that most of them were not successful in their efforts. The constraints encountered by the RTOs reinforced the view that even though globalization opens many opportunities for business, it also creates major challenges. One of the most important challenges is acknowledging and appreciating cultural values, practices, and subtleties in different parts of the world (House, 2004). Managers needed the flexibility to respond positively and effectively to practices and values that may be drastically different from what they are accustomed to (House, 2004). it is therefore, hypothesized that the extent to which the RTOs attempts to implement and internalize the ten management practices was influenced by activity contradictions in the form of situational problems, conflicts and tensions induced by individual and 
group behaviours in their organizational activity systems. Based on this hypothesis, the following research question is raised; can change managers in organizations simultaneously identify and positively exploit the development of the individual and group based behavioral-induced contradictions towards effective management of organizational change processes?

The purpose of this study is to determine the individual and group behavioral-induced situational problems, conflicts and tensions that change managers can identify and also use as innovative tools to enhance their capacity to manage organizational change.

\section{Literature Review}

Organizations are loosely coupled arrays of standardized elements (DiMaggio \& Powell, 1991) or archetypes (Greenwood \& Hinings, 1993) which are interrelated. Since the notion of interrelatedness suggests a social system (Kast \& Rosenzweig, 1985), organizations consist of the following elements or archetypes; - goal oriented arrangements (i.e. containing people with a purpose), psychosocial systems (i.e. with people interacting in groups), technological systems (i.e. with people using knowledge and techniques), and an integration of structured activities (i.e. with people working together in patterned relationships) (Kast \& Rosenzweig, 1985). On the basis of behavioral studies of organizations and a critique of the rationalistic theories, Levitt and March (1988) viewed actions in organizations to stem from historically formed routines that develop incrementally. Levit and March (1988) argued that even within a single organization, there are severe limitations to organizational learning as an instrument of intelligence. This argument supports the notion that learning in an organization does not always lead to intelligent employee behaviour, because organizational processes that are expected to yield employees' experiential wisdom, also creates among the employees, superstitious learning, competency traps, and erroneous inferences. Such dual influences of organizational processes on employees learning shows that problems organizations usually encounter when their employees sought to learn from experiences are partly due to the inadequacies of their employees' cognitive habits, the organization's features, and structural characteristics of experiences in the organization.

Though there are strategies for ameliorating some of these problems, ordinary organizational practices do not always generate behaviors that could conform to such strategies (Levit \& March, 1988). Weick and Roberts (1993) have argued that a well-developed organizational mind, capable of reliable performance and built from the dense interrelations in an organization, is thoroughly social. Based on this argument, interpersonal skills in an organization that aims at developing a high-reliability organizational system should not seen as a luxury, but rather as a necessity. This is because, these skills enable employees in organizations to represent and subordinate themselves to communities of organizational practice. By implication, as people move toward individualism and fewer interconnections, the organization's mind is simplified and soon becomes indistinguishable from the individual mind (Weick \& Roberts, 1993). Thus, to analyze the evolution of an employee's individual sense-of-self, the context of which it is an agent of the social might need to be looked at. This analysis, as Spender (1996) explained, does not imply social determinism, but is rather based on the notion that social influence in an organization is mediated by an irreducible or random element of individuality. The argument here is that organizations learn and have knowledge only to the extent that their members are malleable beings whose sense of self is influenced by the organization's evolving social identity (Spender, 1996). Since organizations are comprised of several "communities of practice" that often cross the formal boundaries of organizational units, organizational learning should be studied by analyzing how these networked communities of practice create new insights, and learn (Brown \& Duguid, 1991). This organizational learning differs remarkably from what managers and planners of personnel training seem to assume (Virkkunen \& Kuutti, 2000). In this respect, Spender (1996) argued for a synergistic sense of collective organizational identity that is different from the mechanical sharing of knowledge which treats an organization's identity as a mere classificatory device (i.e. a way of identifying which individuals share a particular body of knowledge). Even though such synergistic sense of collectiveness have its limitation in providing much insights on specific social features influencing an individual's sense-of-self, "it does move us towards a 'social constructionist' position in which we focus on the dynamics of the individual's institutional context" (Spender, 1996, p. 53).

Organizational learning is a complex interplay between different elements of an organizational system, and it can be studied by taking the whole system as the unit of analysis and intervention, rather than reducing it to one or another element (Virkkunen \& Kuutti, 2000). Organizational learning is always local and situational, with structures, practices, habits and ways of thinking in an organization all shaped and produced in the historical development of that particular organization (Virkkunen \& Kuutti, 2000). Thus, the dynamics of organizational transformation from a current situation to a new one cannot be done without a historical perspective (Virkkunen \& Kuutti, 2000). Arguing from the perspective of Spender (1996) relative to the operationalization of a 
knowledge-based theory of the firm, it is important to draw a distinction between the systemic and componential aspects of an organization's activity system by understanding how to manage the system's boundary in order to maintain its interpretive flexibility. As Levit and March (1988) found in their study, the lessons of history encoded in organizational routines provide important basis for the understanding the intelligence of organizations. The signification of this finding towards the design of learning organizations is that, it proposed the need to understand the difficulties associated with designing the process. This difficulty is related particularly to the extent to which intelligence in learning is often frustrated, and the extent to which the comprehension of history may involve slower rather than faster adaptation, imprecise rather than precise responses to experience, and abrupt rather than incremental changes (Levit \& March, 1988). The historical and situated construction processes in an organization are mutually constitutive (Gunnarsson, Linell \& Norberg, 1997), thereby opening up the challenge of finding out how the mutual constitution between historical and situated processes actually happen, as well as how it could be empirically captured (Engeström et al., 2003). Historical analysis of an organization's activity system implies that the organizations' broad institutional and social framework is analyzed from a long-time perspective, while the situated analysis implies focusing on the here-and-now, typically on what can be captured on tape in a given situation or single encounter (Engeström, Engeström \& Kerosuo, 2003).

There are different types of distances between practical activity and discourse. In this context, most professional activities fall in the middle of such distances where practical activity is neither replaced nor accomplished solely by talk, but is rather accompanied and complemented by the talk (Engeström, 1999). In this respect therefore, the notion that history is made in future-oriented situated actions (Engeström, 2004) could be used to capture of how employees and their managers discursively create new forms of activities in their organizations by making these situated history-making activities visible and analyzable.

\subsection{Theoretical Framework}

In this study, an organization theoretical approach based on Marxian categories and propositions is used to understand the community of practices, and the social meaning of routines and the values in an organization's constrained efforts towards organizational transformation. This is based on the argument that the Marxian categories and propositions have a strong explanatory power to provide insightful understanding of the functional dynamics of different subsystems in the activity system of a transforming organization (Marx, 1973; Engeström, 1987; Blackler, 1993; Jazarbskowski, 2003; Heydebrand, 2008). Using this framework, the concepts of "productive force" and "social relations of production" (Marx, 1973) are specified in terms of various organizational phenomena such as organizing activity versus organization; historical contradictions between organizational control structures and new forms of organizing work activity (Engeström, 1987; Sanda, 2006; Heydebrand, 2008). The contradictions between organizational dimensions as labour-power and its manifestations in terms of skills and knowledge, the division of labour, and the organization of labour (e.g., either in terms of corporate management, or self-organization and workers' control) are also considered of significance. In this framework, organizational contradictions between functional as well as historical phases of the work process (Engeström, 1987, 2004; Heydebrand, 2008) are described for work organizations. For example, administrative and technical innovations designed to increase productivity tend to come into contradiction with strategies of established authority structures designed to expand domain, thus impeding or nullifying various organizational reform efforts (Engeström, 2001; Heydebrand, 2008).

An organization's activity system is always a community of multiple points of view, traditions and interests which carries multiple layers and strands of history engraved in its artifacts, rules and conventions (Engeström, 2001). The division of labour creates different positions for the activity participants, who also carry their own diverse histories. This multivoicedness is multiplied in networks of the organization's interacting sub-activity systems (Engeström, 2001; Sanda, 2006), and serves as a source of both trouble and innovation, which demand actions of translation and negotiation (Engeström, 2001). Since the organizational activity systems also get transformed over lengthy periods of time, the problems and potentials inherent in such systems can be understood only against the system's own history (Engeström, 2001). The activity systems' history needs to be examined, not only as a local history of the activity and its objects, but also as a history of the theoretical ideas and tools that have helped shape the activity. Thus in examining constraints to the management of organizational change, the challenge is to make the situated history of the contradictions in the organization's activity system visible and analyzable (Engeström, 2001, 2004; Sanda, 2006). This implies finding ways of capturing how individuals and groups discursively create new forms of activities that question or overlap with those new activity norms being introduced in the organization's activity system.

Since organizational change is a difficult, time consuming, and expensive process, internal factors, including the 
way people interact with each other in an organization and commit themselves to organizational goals, are complex matters for which an understanding is needed (Shahnavaz, 2002). Organizational change must be seen an attempt to reorganize or re-mediate the activity system in order to resolve its pressing inner contradictions (Engeström, 1987). Thus in the process of organizational change, activity contradictions play central role as sources of change and development (Engeström, 1987, 2001). In this context, contradictions are not the same as problems or conflicts, but are historically accumulating structural tensions within and between activity systems (Engeström, 1987, 2001). Since activities are open systems, all elements of an organization's activity system are pervaded by primary contradiction in the process of organizational change (Engeström, 1987). This implies that when an organizational activity system adopts a new element from the outside, for example, a new technology or a new practice, the primary contradictions are often aggravated to secondary contradictions (Engeström, 1987). When the organizational activity system is in a secondary contradiction state, collision between some old system elements being transformed, for example, the rules or the division of labour, and the new system's elements being introduced, could occur (Engeström, 1987). This collision generates not only disturbances and conflicts in the organizational activity system, but also provides platform for generating innovative ideas on how to change the activity (Engeström, 2001). For example, the aggravation of contradiction will cause some individual participants in an activity to question new practices being introduced into the organizational activity system and by implication deviate from newly established norms. In some cases, this escalates into collaborative envisioning and a deliberate collective change effort (Engeström, 2001, 2004).

\subsection{Methodological Considerations}

Qualitative research tends to require thoughtful analysis of the relationship between the data sources and the findings that derive from them. This is because it can be almost impossible for a researcher to untangle the shared component of a subjective experience from the narratives that people place experiences (Thorne, Reimer $\&$ MacDonald-Emes, 1997). In this respect, it is important to give an interpretive description that could generate knowledge on the internal factor that constrained the implementation of the best management practices model by the RTOs in developing countries (Sanda, 2011). Giving such interpretive description requires purposeful selection of research participants whose accounts could reveal elements that were shared by others (Sanda, 2010). Qualitative researchers, such as Morse (1989) and Thorne et al. (1997) contended that people who have lived with certain experiences are often the best source of expert knowledge about those experiences. Thorne et al. (1997) also argued that not all the people who have such experiences would make good research participants. This is because, while some subjects would be articulate, thoughtful, and eager to share their abstractions and analyses of a situation being studied, others would tend to be more concrete and more comfortable with events than interpretations (Thorne et al., 1997).

\subsubsection{Building the Qualitative Design}

The mode of understanding implied by qualitative research involves alternative conceptions of social knowledge, meaning, reality, and truth in social science research. As such, the basic subject matter is no longer objective data to be quantified, but meaningful relations to be interpreted (Kvale, 1996). It is the insight to be gained from such meaningful relations, as entrenched in the organization's societal environments that stood to add value to the understanding of the relative outcome of the new practices model it tried to implement and internalize. In this regard, Kvale (1996) argued for a move away from obtaining knowledge primarily through external observation and experimental manipulation of human subjects towards an understanding by means of conversations with the human beings to be understood. In this study, Kvale's argument of the need to obtain knowledge by understanding human beings through the medium of conversation (i.e. interviews) is used as a relevant tool for data collection. Since the study is centered around one organization (i.e. as a case study), a critic view of Kvale's argument for a move away from obtaining knowledge primarily through external observation and experimental manipulation of human subjects was taken. In this study therefore, an interpretive analytic framework (Thorne, et al., 1997; Sanda, 2010) is used as an appropriate platform to build a qualitative design. Such framework orients a study, provide a rationale for its anticipated boundaries, and makes explicit the theoretical assumptions, biases, and preconceptions that drive the design decisions. Since the framework is explicit in the description of what is being studied, it also provides a solid basis upon which the design logic and the inductive reasoning in interpreting meanings within the data are judged (May, 1989).

\subsubsection{The interview Approach}

Though there are different kinds of interview approaches, the schedule standardized interview (SSI) form was used in this study. This provided an avenue in the interview process to create a platform based on which the interviewees answered not only the lead questions prepared for them, but they also had the opportunity to 
formulate their own conceptions of constraints in the organizations in which they worked during the interview conversation. Denzin (1989) viewed the SSI format to entail the problem of fabrication and in securing respondents' interest which makes it difficult to convey meaning. Such concerns are derided by hermeneutics (Sanda, 2010). Kvale (1996) explained hermeneutics to elucidate the dialogue that produces the interview texts to be interpreted. Thus, the rationale for choosing the SSI approach in this study was provided by the interviewees having a sufficiently common vocabulary by virtue of the homogeneity of their working environment (Richardson, Dohrenwend \& Klein, 1965). Based on this perspective, the content of the interview instrument with respect to the wording and order of all the questions were exactly the same for each interviewee. The reason for this was to retain the uniformity of the interview instruments as tool for dialogue elucidation (Sanda, 2010). The advantage derived here was that each of the questions in the interview instrument became the lead question that opened up as well as facilitated the interview conversation. The interviewees were in environments with no language diversity and also without the fear of talking to the researcher. This was by virtue of the management of the organization indicating interest and full cooperation in this study.

\section{Materials and Methods}

\subsection{Data Collection}

Data was collected from a Caribbean-based organization that tried to implement and internalize the RTO management practices towards enhancing its employee performances for efficient and effective service delivery to clients. Before gaining access to the study participants, contact was firstly established with the organization (through its Chief Executive Officer) to know if the management was prepared to support the study by allowing unhindered access to employees from whom data could be sourced. The management, in turn, sought an understanding of the research purpose and the expected learning that their organization could derive from the findings. A short research synopsis was prepared and sent to the organization's management. This aided their understanding of the research purpose. Based on this, a commitment of support and cooperation towards unhindered access to data collection was received from the organization's management. The study participants were selected using the snowballing (Patton, 1990) technique, derived from the researcher's criteria that persons to be selected for the study (i.e. data sources) must "have-lived" the privatization process and thus have knowledgeable insights of the changes in the work environment.

The data was collected through interviews (i.e. conversations) with 19 employees. All the interviewees were identified to have played variety of key roles in the organization's privatization process from its onset. As such, their individual implicit beliefs concerning attributes and behaviours that distinguished effective leadership actions from ineffective leadership actions during the process were sourced in the interviews. All the interviews were audio-recorded, each session lasting an average time of one hour. The duration for data collection was two weeks.

\subsection{Data Analysis}

The interpretive description qualitative approach (Thorne et al., 1997; Brazier, Cooke \& Moravan, 2008) was used to analyze the scripts generated from the interviews. Using this approach, the experiences of the interviewees in relation to how actions in the work environment constrained the implementation and internalization of the ten management practices in the organization is described and interpreted. The description and interpretation is done without reconfiguring it into a more highly interpretive form. Instead, findings were made to stay closer to the words of the interviewees and described their experience, while at the same time capturing the meaning they attributed to this experience (Brazier et al., 2008).

The recorded interviews were transcribed and scripted (Kvale, 1996). The validity of the scripts generated for all the interviewees was established after crossing-checking with each interviewee. Interpretive description analysis was conducted to understand the characteristics of the organization's internal environment, and the type of constrains that infected the work environment. This was because in the dialogue (i.e. interview conversation), the subjects (interviewees) did not only answer the questions prepared by the researcher (interviewer), but they (interviewees) were also given the space to formulate their own conceptions of their lived world (Kvale, 1996). The expectation here is that the sensitivity of the interview approach and its closeness to the interviewees' "lived world" would lead to the generation of knowledge that could be used to understand the internal factors that constrained the practices implementation process of the organization studied. As such, the interview was a conversation about the interviewees "lived world" during the process, with the oral discourse transformed into texts to be interpreted (Kvale, 1996). Since the purpose of hermeneutical interpretation is to obtain a valid and common understanding of the meaning of a text, then hermeneutics is of double relevance to interview research (Kvale, 1996). Kvale explained that aside elucidating the dialogue that produces the interview texts to be 
interpreted, hermeneutics, also clarifies the subsequent process of interpreting the interview texts that are produced, and which may again be conceived as a dialogue or a conversation with the text. Since it can be almost impossible for a researcher to untangle the shared component of a subjective experience from the narratives that people place them in, qualitative research requires thoughtful analysis of the relationship between the data sources and the findings that derive from them (Thorne et al., 1997). With this observation in mind, the actions and activities of individuals and groups in the organization which were cited by the interviewees to have contributed in constraining the organization's implementation and internalization of new practices in the work environment are analyzed. This analysis was carried out using the activity analysis technique (Engeström, 2001). The main unit of analysis is the organization's activity system. The sub-units of analysis are the goal-directed individual and group actions, as well as automatic operations, in the organization.

Using the activity analysis technique, the expressions of the interviewees were appraised and meanings ascribed them in order to understand the dynamics of change in the organization. The appraisal was guided by the following four steps: (i) Goal-directed individual and group actions were appraised to identify the existence of multivoicedness (i.e. sources of tensions and troubles, and also innovation which demand actions of translation and negotiation) in the organization's activity systems; (ii) Both problems and potentials identified in the organization's activity systems were appraised and understood against their own historical transformations; (iii) Contradictions (i.e. historically accumulating structural tensions within and between activity systems that served as sources of change and development) in the different elements of the organization's activity system were identified; (iv) Emergence of possible expansive transformations in the organization's activity system due to employees' questioning and deviation from organizational norms were also identified.

\section{Results and Discussion}

In order to enable the understanding of the functionalities of specific elements embedded in the different components of the organization's activity system, and also the effect of both individual and collective activities during the organizations change process, the analytical results are presented and discussed from the perspectives of the following three themes: (i) Functionality of the organization' management structures, (ii) Managing the organization's psycho-social environment, (iii) Re-orientation of organizational values and norms.

\subsection{Functionality of the Organization's Management Structures}

At the start of the organization's efforts to implement and internalize the Best Management practices (BMP) model, the organization's institutional structures which were civil service-oriented and highly bureaucratic. This structure did not undergo the requisite transformation underlined by the implementation of the BMP model. It was understood from the interviews that the rules that safeguarded the functioning of the organization's bureaucratic institutional structures were underlined by two major civil services codes, namely, the condition of service and the scheme of service. The interviewees' perception of these rules was that the application and subsequent functionality of these rules were shrouded by complicated bureaucratic procedures which impacted negatively on the organization's BMP model implementation and internalization efforts. A picture of this was drawn by an interviewee in the following expression;

We had internal rules which could be categorized into three forms. Firstly, we had the condition of service, secondly, the scheme of service, and thirdly, some minor regulations and policies on housing and the like. The condition of services, which guided the organization's operations, was strictly based on that for all government institutions in the country. Even our job titles were derived from those pertaining in the civil service. The scheme of service outlines issues concerning recruitment and placement of staff members. Yet, these rules were flouted a lot, especially by the heads of departments who had authoritative power over the human resources manager to the detriment of staff members in the organization.

The organization, according to most of the interviewees, had some informal rules which were observed as if they were formal in contrast to the requirements of the best management practices model. The proliferation of such informal rules was viewed by most of the interviewees to have created a situation whereby most people in the organization did things their own way, and in the process created an atmosphere of inconsistent approach towards organizational activities. In this respect, the informal rules that prevailed in the organization significantly shaped the attitudes and mindset of most of the staff members towards the acceptance changes in their work practices. As a consequence, most of the interviewees perceived the institutional structures that prevailed during the BMP model implementation and internalization efforts to have lacked both functional and directional clarity. This created a work environment in which organization's activities entailed tasks duplication. An explanation to this observation is reflected in the following expression by an interviewee;

With respect to my unit, internally, management referred to it as a unit, but to the outside world, they called it a 
department, which to me sounded like they were cheating us. They only realized our importance when they go out. Internally, they did not realize the importance of our unit. Sometimes you get calls from people outside asking for information, but then you realize that that your area was covered by someone else. There were lots of duplication in the organization and we seem to have fallen in between.

The interviewees viewed the informal rules to have filled the apparent gaps left by the formal ones that were to have emerged from the BMP model implementation and internalization process. The consequence of this was that the mind-set and attitudes of most staff members towards the BMP model implementation and internalization efforts was non-committal, in sharp contrast to the expectations of the management. Most of the staff members were viewed by the interviewees to have sustained their perception of the organization's old identity as due to the frequent changes of managers in the organization during BMP model implementation and internalization process. This observation is pictured in the following expression by an interviewee;

In the past we used to have different visions and missions which were written in different ways. We also had had three managing directors changed since we started organizational transformation process. Some managers did not stay at their post long enough for them to be able to implement any sort of strategy. The organization had system of other government and public institutions, whereby you could come to work and choose to work, or not to work, but you still get paid at the end of the month.

There was the generally held notion among the interviewees that during the BMP model implementation and internalization processes, the various managers in the organization did not make significant attempts to reorient the institutional rules to reflect the requirements of a business-oriented research and technology organization. The same old rules were adopted in all the new structures created in the organization systems during the BMP model implementation and internalization efforts. The incompatible amalgamation of the old rules with the new structures resulted in numerous failures to strengthen the organization's operations. A reflection of this observation can be derived from the following views as expressed by an interviewee;

I think the rules that guided our operations were the old rules which were adopted into the new system. They were never changed. In fact, they were not consistent with the way we were supposed to function. If we continued to have confusion about the structure of the organization, then how could we really have gotten a clear picture of the division of labour? I think the management structure was not right. Actually, we did not have the foundation for building a research institution as it pertained in most countries. I saw the human resource manager more as an advisor to the management and hence did not have the power to take decisions. This manager was not a member of the organization's management.

It is indicative from the observation above that the organization retained its hierarchical structure and continued to use civil service institutional codes as the definitive source for its structural and management system designs. The retention of the hierarchical structure conflicted with the horizontal management structure professed by the BMP model. This conflict constrained the organization's ability to implement the various strategic plans developed from the BMP model. This scenario reflects the context of the management's attempt to change ways of doing things in the organization while at the same time retaining the old structures which necessitated the change. It also reflects the conflicts in organizational governance by the attempt to make new strategies function under the old institutional rules. Therefore, the retention of the organization's institutional characteristics during the BMP model implementation and internalization efforts created contradictions in the organizational structure that inhibited both individual and group performances. Engeström (2001) noted that contradictions generate not only disturbances and conflicts in an organizational activity system, but also innovative attempts to change the activity. The disturbances and conflicts generated by the contradictions constrained the organization's efforts to introduce the BMP model-related practices on corporate governance, personnel management and project management, all of which could have facilitated the effectiveness of its operations.

\subsection{Managing the Organization's Psychosocial Work Environment}

The retention of the old management structure made it difficult to institute the regulations, operating assumptions, power structures, as well as reward and status systems defined by the BMP model-oriented practice for personnel management which required inputs from managers and the workers alike. The interviewees related the difficulty to the creation of class distinctions in the work environment. The staff members were classified into three main groups whose distinct identities were shaped by the hierarchical management structure. These distinct groups were the management team, senior staff (i.e. researchers/scientist) and junior staff (i.e. technical and administrative support personnel). The rationalization of such class distinction created tension and conflicts among the three different groups due to their uncomplimentary existence. Work activities in the organization were saddled with problems caused by recurring factional in-fighting between the different classes of workers. 
The core of these problems was traced by the interviewees to the issue of role play and the extent to which such roles were played by staff members or by a unit and/or division. The tension that emerged among different units in the organization was related by the interviewees to a development during the BMP model implementation and internalization process. The organization's management reprimanded staff in some divisions for showing uncommitted attitude towards the BMP model implementation and internalization efforts. The affected staff members sought to prove their commitment by working alone rather than collaborate with others in the organization. This self-approach to tasks resulted in individual staff members perceiving themselves as project initiators, project developers and project implementers in the organization, contrary the BMP model practices for organizational management, business development and project management as provided by the best management practice model. This situation introduced tension in the organization's work environment and made work collaboration and cooperation among workers in different units and divisions of the organization a difficult task, as it is reflected in the following expression by an interviewee.

We had a situation where someone came up with an idea. We tried as much as possible to involve people from other units, but the mentality right was that of isolation. Each unit wanted to have its own project, and this idea is not good for the organization. I think these are among the things that have led to projects not being seen as the organization's project, but rather, as a unit's project. Also, some staff members did not support projects undertaken by units different from their own, because in their opinions, such supports would have made other units become better than theirs.

The polarization of the organization's working environment and the tensions it generated was credited by interviewees to a situation in which units belonging to same departments simultaneous undertook different projects, and which events culminated into unhealthy competition for same resources. It was also revealed in the interviews that severe differences existed between staff in the organization's marketing department and researchers in the organization's technology department. This tension was as a result of the technology division's objection to the key role that the marketing division was to play in the BMP model implementation and internalization process. The marketing department was to be responsible for handling awareness and market strategic planning, as against its previous role of only liaising between the technology division and clients. The interviewees perceived the interaction between the two divisions as unhealthy, as they virtually disagreed with each other on all project-related issues. This conflict led project managers to usurp the functions of the finance unit, and spent enormous time preparing bills (work of the finance unit) rather than focusing on the research aspect of projects. This conflict added to the inefficiency of the work organization, because bills prepared by the project managers were re-examined for correction by the finance unit, resulting in double work. This conflict is reflected in the following expression by an interviewee;

The people in the research teams sat down and did their own things. They only came to finance when they needed the money. This was the greatest error we committed. This was completely against the best practices being introduced in the organization. Staff from Finance was normally not involved at the beginning of projects. Finance also sat down and looked at the financial submissions made to it purely from financial point of view. This caused delays in service delivery to clients.

The reporting system that prevailed in the organization was also viewed by the interviewees to be too long and cumbersome. In this system, a unit manager in a division reported to a project manager within the division. The project manager also reported to the director of the division, who in turn reported to the organization's head. By this arrangement, as it was explained in the interviews, the project managers were superior to the unit managers. At the completion of projects, the project managers' positions faded out, and those who occupied the position became subordinates to their unit managers. The consequence of this was that projects initiated were carried out haphazardly and poorly managed. This observation was put into perspectives by an interviewee as follows;

When it came to the issue of collaboration, I got disappointed. I still think that we have a long way to go in this direction. When you are part of a team in a project, it was very difficult to send your message across to the rest of the team members...... If someone from another unit manages a project team, the person sees the team members as his workers and expects them to be with the project till it is finished. Yet, conflicts emerged along the line, because instead of team members working on the project, they normally ended up busily doing something in the units from which they were drawn into the project. This did not encourage networking.

Based on the above appraisal, it can be inferred that the approach used to manage the work organization and the psychosocial environment during the organization's BMP model implementation and internalization efforts had no clear outlines. As it was noted earlier, networking did not exist among the different units and/or divisions in the organization. Cooperation was virtually absent due to the conflict and tensions that prevailed in the work 
environment. The consequence of this contradiction was the phenomenon in which individuals and groups in the organization's units and/or divisions held on to their self-carved identity. This resulted in the malfunctioning of project teams. This scenario reflects Engeström's (2001) explanation that when an activity system adopts a new element (for example, the BMP model) from the outside, it often leads to a state of tensions and conflicts where some old elements (for example, the work organization) collided with the new ones being implemented. These tensions and conflicts are conceptualized as a generative process of continuity and displacement between old and new members, in which new members learn from continuing members how to use the practices of the system, and in the process re-socializing the continuing players and reinforcing the existing practices (Jarzabkowski, 2003). The new members, by virtue of their low socialization to the system, also questioned the practices (Lave \& Wenger, 1991; March, 1991; Hutchins, 1993). This questioning is based on the perspective that distribution enables collective action because individual actors have sufficient knowledge of the other immediate components of activity to conceptualize and respond to actions that are outside but connected to their own task (Hutchins, 1993; Weick \& Roberts, 1993; Blackler, 1995). Distribution refers to the context and action engaged in by actors in the organization, and the overlapping knowledge that is involved in their actions (Jarzabkowski, 2003). The widely distributed interaction between the actors, structures and actions in the organization provides systemic knowledge on how change managers can learn to act strategically (Spender, 1996). Thus an enabling distribution enhances shared interpretations and collective action (Jarzabkowski, 2003).

\subsection{Re-Orientation of Organizational Values and Norms}

There was the general impression among the interviewees that the organization's culture (and the norms associated with it) during the BMP model implementation and internalization process was not definitive in terms of consistency and clarity. It was rather reflective of the bureaucratic rigidity that was associated with the organization's institutional structures. This critic was against the background that even though the management tried to use different approaches and styles in handling of the organizational changes, they did not create the kind of culture that could bring the organization's stakeholders together. The organization was described by the interviewees to have had a scattered culture in which different departments defined their own values and norms, as it is reflected in the following comment;

We were not integrated. We did not have inter-functional teams. Each team was defending its own unit within its own department. Every department head was defending his department. We were not working as one. I saw a copy of the BMP model and brushed through it. I foresaw a problem of its implementation succeeding, because the organization had the same mind-set, the same culture, and the same leaders. I thought that maybe, such a best practice model should have come out after the organization had revived itself. We had these solutions, but for what problems, nobody understood.

The phenomenon of scattered-culture highlighted in the interviewee's comment above, created problems of power struggle related to empire building in the organization's operating environment. Most staff members were described by the interviewees to have developed the general feeling that their respective units and/or divisions represented their empires. The heads of these units and/or divisions were also cited by the interviewees to have continued hiring new people into their units and/or divisions. The underlying notion for the recruitment was that; - the larger the number of employees in a unit, the more important and powerful it is in the organization. Due to the relative entrenchment of the scattered-culture, most of the BMP model oriented changes in the organization were resisted. The interviewees related this resistance to the fear of the unknown among the staff members who were comfortable with the old ways of doing things in the organization. The frequent replacements of the organization's Heads were also perceived by most of the interviewees to have aggravated the scattered nature of the organizational culture, as it is highlighted by the following two interviewee's comments;

The reason why this organization suffered in its BMP model implementation and internalization efforts was due to the absence of a substantive head. A month after I arrived here, we lost the managing director. I was very disappointed. Then we got somebody to act. Yet, according to government directives, he could not act beyond a certain period of time, so he had to leave. Overnight we were given a new head, and that person was here for five months only. He was very suspicious of us, and we were also suspicious of him, because we did not know him. So there were lots of tensions.

When we lost our managing director, my understanding was that there were lots of problems that prevailed, but which were not dealt with. It ended up with people forming groups within this organization, so the organization started not to function as one. This resulted in people defending territories. Even when proposing projects, people will defend their territories. I think that was part of the problem, and that was part of what might have caused people into taking projects that did not fulfill the organizational change mandate, because they wanted to 
be seen to be doing something.

The cultures and values of individual staff members were also viewed by the interviewees to have constrained the organization's BMP model implementation and internalization efforts. Most of the staff members were perceived by the interviewees to have displayed attitudes which depicted them as individuals unwilling to accept changes in the organization. This mind-set of the staff members prevailed due to their misunderstanding of the organization's vision and mission. The management also did little to impart on the staff such understanding. The impact of this was narrated by an interviewee as follows;

There was nothing like a corporate culture here. Our management struggled to have it here. They struggled to find whether we were this or that. The organization was sick, in terms of socialization. Though we were professionals, we did not have much of a social interaction.

It can be inferred that the management did little to overhaul the organizational structure as well as the operating systems during the management practices implementation and internalization process. The organization retained its identity as an entity with a weak management system. The inability of the change managers in the organization to carve out a new corporate culture for the work environment resulted in individual interpretations of organizational values, suspicion, distrust, and competition for power and supremacy. The distrust in the work environment made the staff members suspicious of the various ideas conceived by the organization for the management practices' implementation and internalization. This view was corroborated by the participants at the problem-identification workshop who identified organizational culture as a critical problem.

Based on the analyses, the dictating factor in the organization's implementation and internalization of the management practices is informed by its inability to deal with contradictions between the functional elements embedded in the organization's activity system. The functionalities of these elements defined the systemic function of the collective activity system and the constrained output that emerged from it. The systemic function of the organization's activity system is understandable from the systemic approach that looks at societies and social institutions as systems in which all parts depend on each other and work together to create equilibrium. Using this perspective in the analysis, the existence of contradictions (i.e. tensions and conflicts) in the organization's activity system was acknowledged (Engeström, 1987). The extent to which the organization was able to handle conflicts and disturbances during its commercialization processes was dependent on the extent to which it was able to manage the systemic characteristics of its organizational activity systems. The objective for the organization's implementation and internalization of the new practice model was created by the production interface of its organizational activity system (Marx, 1973; Engeström, 1987; Sanda, 2006). The theoretical expectation here was that such an income-generation oriented objective will be divided up by the distribution interface of the organization's activity system, after which it was to be parceled out by the exchange interface in accordance with its collective needs (Marx, 1973; Engeström, 1987). By this theoretical perspective, the unifying process that the interfaces of production, consumption and exchange are expected to create in the organization's activity system during the new practices implementation and internalization process did not materialize. The production that emerged from the process was unable to generate the requisite outcome expected by the organization. Even though elements of distribution seem to be apparent in the organization's collective activity system, its exchange did not materialize as a result of the contradictions (i.e. tensions and conflict) that pervaded the system.

The analyses provided learning on the need for change managers to understand the functionality of such organizational activity elements as the institutional rules, the community and the division of labour when using the best management practices model as an instrument of change. This is because many of the analytic strategies for examining mediated action are made possible by the fact that the elements of such actions can be isolated (Wertsch, 1998), as it was done in the analyses section. The analyses also showed that the tension and conflicts between elements of the organization's activity system identified areas where the system no longer matched the activities it was expected to model as a consequence of the new practice model implementation and internalization (Collins, Shukla, \& Redmiles, 2002).

\section{Conclusion}

This study has shown that the internal constraining factor in an organization's effort to implement and internalize new practices model is the organization's inability to identify and manage the influence of situational problems, such as tensions and conflicts, in its organizational activity system. The study has shown that the systemic function of an organization's activity system is understandable from the systemic approach that looks at societies and social institutions as systems in which all parts depend on each other and work together to create equilibrium. By implication, change managers must understand the functionality of the organizations' activity system when 
adopting new practices models as instruments of change. By this understanding, the existence of conflicts in the system must be acknowledged and ways of controlling it, and using it to energize action, encourage self-evaluation, stimulate innovation and adaptation must be developed. This is because mediated actions in the organization's activity system can be examined by isolating the system's parts. Isolation of the system's parts will provide change managers various specialized perspectives and insights on understanding how to identify, isolate, and manage areas of conflicts and tensions where new activities evolving from the implementation and internationalization of new practices models are constrained.

Though the use of one organization as the basis of this is study a limitation, the findings provides an empirical-based understanding of the constraining impact of internal factors on an organizational change effort, which learning can be by used managers to guide the dynamics of transformational activities in their organizations. By implication, change managers can use the insight provided as a practical resource to understand the significant impact of contradictions in their organizational activity systems, not only as source of tensions and troubles, but also as source of innovation to overcome potential challenges to their organizational change efforts. The study has also provided an understanding with both practical and theoretical values (i.e. from the perspectives of organizational learning) on how organizations can learn to deal with internal factors in their future efforts towards the implementation and internalization of new practices model (as instrument of change).

\section{References}

Blackler, F. (1993). Knowledge and the Theory of Organizations: Organizations as Activity Systems and the Reframing of Management. Journal of Management Studies, 30 (6), 863-864, doi:10.1111/j.1467-6486.1993.tb00470.x, http://dx.doi.org/10.1111/j.1467-6486.1993.tb00470.x

Brazier, A., Cooke, K., \& Moravan, V. (2008). Using Mixed Methods for Evaluating an Integrative Approach to Cancer Care: A Case Study. Integrative Cancer Therapies, 7 (1), 5-17, doi:10.1177/1534735407313395, http://dx.doi.org/10.1177/1534735407313395

Brown, J. S., \& Duguid, P. (1991). Organizational Learning and Communities of Practice: Toward a Unified View of Working, Learning and Innovation. Organization Science, 2 (1), 40-57, doi:10.1287/orsc.2.1.40, http://dx.doi.org/10.1287/orsc.2.1.40

Collins, P., Shukla, S., \& Redmiles, D. (2002). Activity Theory and System Design: A View from the Trenches. Computer Supported Cooperative Work, 11 (1-2), 55-80, doi:10.1023/A:1015219918601, http://dx.doi.org/10.1023/A:1015219918601

Denzin, N. K. (1989). The research act: A theoretical introduction to sociological methods. (3rd edn). Englewood Cliffs, NJ: Prentice Hall

DiMaggio, P., \& Powell, W. W. (1991). Introduction: The new institutionalism in organizational. In W. W. Powell, \& P. J. DiMaggio (Eds.). The new institutionalism in organizational analysis (pp. 1-38). Chicago: The University of Chicago Press

Engeström, Y. (1987). Learning by expanding: An activity-theoretical approach to developmental research. Helsinki: Orienta-Konsultit

Engeström, Y. (1999). Communication, Discourse and Activity. The Communication Review, 3 (1), 165-185, doi:10.1080/10714429909368577, http://dx.doi.org/10.1080/10714429909368577

Engeström, Y. (2001). Expansive Learning at Work: Toward an Activity Theoretical Reconceptualization. Journal of Education and Work, 14 (1), 133-156, doi:10.1080/13639080123238, http://dx.doi.org/10.1080/13639080123238

Engeström, Y. (2004). Managing as argumentative history-making. In R. J. Boland, \& F. Collopy (Eds.). Managing as designing (pp. 96-101). Stanford: Stanford University Press

Engeström, Y., Engeström, R., \& Kerosuo, H. (2003). The Discursive Construction of Collaborative Care. Applied Linguistics. 24 (3), 286-315. doi:10.1093/applin/24.3.286, http://dx.doi.org/10.1093/applin/24.3.286

Greenwood, R. A., \& Hinings, C. R. (1993). Understanding Strategic Change: The Contribution of Archetypes. Academy of Management Journal, 36 (5), 1052-1081, doi:10.2307/256645, http://dx.doi.org/10.2307/256645

Gunnarsson, B. L., Linell, P., \& Norberg, B. (1997). Introduction. In B. L Gunnarsson, P. Linel, \& B. Norberg, (Eds). The construction of professional discourse. London: Longman

Heydebrand, W. (2008). Organizational Contradictions in Public Bureaucracies: Toward a Marxian Theory of Organizations. Sociological Quarterly, 18 (1), 83-107, doi:10.1111/j.1533-8525.1977.tb02163.x, 
http://dx.doi.org/10.1111/j.1533-8525.1977.tb02163.x

House, R. J. (2004). Illustrative examples of GLOBE findings. In R. J. House, P. J. Hanges, M. Javidan, P. W. Dorfman, \& V. Gupta (Eds.). Culture, leadership, and organizations: The GLOBE study of 62 societies (pp. 3-8). Thousand Oaks, California: SAGE Publications, Inc

Hutchins, E. (1993). Learning to navigate. In S. Chaiklin (Ed.). Understanding practice: Perspectives on activity and context (pp. 35-63). Cambridge: Cambridge University Press

Jarzabkowski, P. (2003). Strategy as Social Practice: An Activity Theory Perspective on Continuity and Change. Journal of Management Studies, 40 (1), 23-55, doi:10.1111/1467-6486.t01-1-00003, http://dx.doi.org/10.1111/1467-6486.t01-1-00003

Kast, F. E., \& Rosenzweig, J. E. (1985). Organization and management: A systems and contingency approach. New York: McGraw-Hill

Kvale, S. (1996). Interviews: An introduction to qualitative research interviewing. Thousand Oaks, California: Sage

Lave, J., \& Wenger, E. (1991). Situated learning: Legitimate peripheral participation. Cambridge: Cambridge University Press

Levitt, B., \& March, J. G. (1988). Organizational Learning. Annual Review of Sociology, 14, 319-340, doi:10.1146/annurev.so.14.080188.001535, http://dx.doi.org/10.1146/annurev.so.14.080188.001535

March, J. G. (1991). Exploration and Exploitation in Organizational Learning. Organization Science, 2 (1), 71-87, doi:10.1287/orsc.2.1.71, http://dx.doi.org/10.1287/orsc.2.1.71

Marx, K. (1973). Grundrisse: Foundations of the critique of political economy. Harmondsworth: Penguin Books

May, K. (1989). Interview techniques in qualitative research: Concerns and challenges. In J. M. Morse (Ed.). Qualitative nursing research: A contemporary dialogue (pp. 188-201). Newbury Park, California: SAGE Publications, Inc

Mengu, M., \& Grier, D. (1999). Best practices for the management of research and technology organizations. Copenhagen: DTI - WAITRO

Morse, J. M. (1989). Strategies for sampling. In J. M. Morse (Ed.). Qualitative nursing research: A contemporary dialogue (pp. 127-145). Newbury Park, California: SAGE Publications, Inc

Negandhi, A. R. A. (1977). Model for analyzing organization in cross-cultural settings: A conceptual scheme and some research findings. In R. Negandhi (Ed.). Modern organizational theory (pp. 285-312). Kent State, OH: University Press

Patton, M. Q. (1990). Qualitative evaluation and research methods. Newbury Park, California: SAGE Publications, Inc

Richardson, S. A., Dohrenwend, B. S., \& Klein, D. (1965). Interviewing: Its forms and functions. New York: Basic Books

Sanda, M. A. (2006). Four case studies on the commercialization of government $R \& D$ agencies: An organizational activity theoretical approach. Doctoral Thesis 2006:33/ISSN:1402-1544. Luleå, Sweden: Luleå University of Technology Press

Sanda, M. A. (2010). Impact of Value-Based Transformational Leadership in Privatizing Government Institutions in a Developing Economy: A Case Study. Business \& Management Quarterly Review, 1 (3), 1-13.

Sanda, M. A. (2011). Conceptualization of Actors' Emerging-Object-Of-Activities as Hidden Exploitative Resource for Managing Organizational Change. Global Journal of Strategies and Governance, 2 (1), 31-41.

Shahnavaz, H. (2002). Macroergonomic considerations in technology transfer. In H. W. Hendrick, \& B. M. Kleiner (Eds.). Macroergonomics: Theory, methods and applications (pp. 311-22). New Jersey: Lawrence Erlbaum

Spender, J. C. (1996). Making Knowledge the Basis of a Dynamic Theory of the Firm. Strategic Management Journal, 17 (Winter Special Issue), 45-62.

Stoecker, R. (1991). Evaluating and Rethinking the Case Study. The Sociological Review, 39 (1), 88-122, doi/10.1111/j.1467-954X.1991.tb02970.x, http://dx.doi.org/10.1111/j.1467-954X.1991.tb02970.x

Thorne, S. Reimer, K. S., \& MacDonald-Emes, J. (1997). Interpretive Description: A Noncategorical Qualitative 
Alternative for Developing Nursing Knowledge. Research in Nursing \& Health, 20 (2), 169-177, doi:10.1002/(SICI)1098-240X(199704)20:2<169::AID-NUR9>3.0.CO;2-I,

http://dx.doi.org/10.1002/(SICI)1098-240X(199704)20:2<169::AID-NUR9>3.0.CO;2-I

Virkkunen, J., \& Kuutti, K. (2000). Understanding Organizational Learning by Focusing on Activity Systems. Accounting, Management and Information Technologies, 10 (4), 291-319, doi:10.1016/S0959-8022(00)00005-9, http://dx.doi.org/10.1016/S0959-8022(00)00005-9

Wallace, R. A., \& Wolf, A. (1991). Contemporary sociological theory: Continuing the classical tradition. (3rd edn.). Englewood Cliffs, New Jersey: Prentice Hall

Weick, K. E., \& Roberts, K. H. (1993). Collective mind in Organizations: Heedful Interrelating on Flight Decks. Administrative Science Quarterly, 38 (3), 357-381, doi:10.2307/2393372, http://dx.doi.org/10.2307/2393372

Wertsch, J. V. (1998). Mind as action. Oxford: Oxford University Press 